\title{
The Improvement of Overtemperature DeltaT and Overpower DeltaT Shutdown Algorithm
}

\author{
Li Gang ${ }^{1, \text { a) }}$ \\ ${ }^{1}$ China nuclear power engineering company, Shenzhen 518124, China. \\ a) ligang7403@aliyun.com
}

\begin{abstract}
Key words: Overtemperature DeltaT; Overpower DeltaT; Digital; Analog technology; Shutdown
\end{abstract} margin.

\begin{abstract}
The Overtemperature OT DeltaT design is based on radial core peaking factors being no worse than design. It is not intended to protect for adverse radial power (quadrant tilt such as might be caused by misaligned control rods). The OT DeltaT RT protects the thermal design limit for departure from nucleate boiling (DNB), with resultant overheating of the fuel rod cladding, by preventing the combination of power, power distribution, pressure, and core inlet temperature that would violate the allowable design limit for the DNB ratio. The DNB ratio also depends upon the coolant flow into the core. DNB protection for flow transients is provided by the reactor coolant low flow RT and by the RCP underspeed RT. Coolant flow is considered constant for the OT DeltaT RT. The Overpower OP DeltaT design is based on radial core peaking factors being no worse than design. It is not intended to protect for adverse radial power. The Overpower OP DeltaT reactor trip protects the core against high linear power density. The article focus on the compare between analog and digital control technology for OT DeltaT, OP DeltaT algorithm. By using the digital control technology, the algorithm and signal process get best improvement. The protect function get more safety.
\end{abstract}

\section{OVERVIEW}

The Overtemperature $\Delta T$ RT protects the thermal design limit for departure from nucleate boiling (DNB), with resultant overheating of the fuel rod cladding, by preventing the combination of power, coolant temperature, power distribution, pressure, and core inlet temperature that would violate the allowable design limit for the DNB ratio. The Overpower OPDeltaT design is based on radial core peaking factors being no worse than design. It is not intended to protect for adverse radial power. The Overpower OPDT reactor trip protects the core against high linear power density ${ }^{[1]}$.

Overtemperature and Overpower $\Delta T$ protection used analog technology before in traditional pressurized water reactor nuclear power plant. The reactor trip setpoint is calculated by means of representation and fitting formula. With the development of sensor measurement technology, core thermal calculation and the application of computer technology in nuclear power plant, Digital instrument and control (I\&C) has been able to support the calculation and modification of the complex core thermal power, and to create prerequisite for the use of more advanced Overtemperature and overpower $\Delta T$ algorithm ${ }^{[2]}$.

\section{OVERTEMPERATURE AND OVERPOWER DELTAT SHUTDOWN FUNCTION UNDER THE CONDITION OF ANALOG CIRCUIT TECHNOLOGY}

The formula of overtemperature and overpower $\Delta T$ shutdown function under the condition of analog circuit technology was applied to the pressurized water reactor from 1966 to $1968{ }^{[3]}$. During the analog circuit technology, instrument control module for processing and calculation was realized by the special circuit design, which requires the computation complexity is too high to be, formula should not be too complex, and module did not have a continuous storage function for the setting value, only through the potentiometer, comparator electronic components achieve the 
setpoint and the compare.

\subsection{OTDeltaT Reactor Trip Function}

There are cold leg temperature measurements and hot leg temperature measurements in each reactor coolant system loop, to form four $\Delta T$ (the difference of hot leg temperature and cold leg temperature) and average temperature $\left(T_{\text {avg }}\right)$ signals.

An overtemperature $\Delta T$ RT shall be initiated if:

$$
\text { Margin OT } \Delta T=\Delta T_{\text {SETPOINT }}-\Delta T\left(1+\tau_{4} s\right) /\left(1+\tau_{5} s\right)<0 \text { in two of the four } \Delta T
$$

The setpoint for $\Delta T$ is variable:

$$
\Delta T_{\text {SETPOINT }}=\Delta T_{0}\left[K_{1}-K_{2}\left(1+\tau_{1} s\right) /\left(1+\tau_{2} s\right)\left(T_{\text {avg }}-T_{\text {avg }}^{0}\right)+K_{3}\left(P-P_{0}\right)-f_{1}(\Delta I)\right]
$$

Guidance: Where

$\Delta T$ : Temperature measurement by RTD and computed DeltaT core thermal power, $\Delta T_{0}$ : Computed DeltaT at rated thermal power

$T_{\text {avg }}$ : Average temperature, $T_{\text {avg }}^{0}$ : Average temperature at rated thermal power

$P$ : The absolute pressurizer pressure (psig), $P_{0}$ : Normal RTP pressurizer pressure

$K_{1}$ : Offset, $K_{2}, K_{3}$ : Gain, to compensate the temperature effect of thermal design limit for departure from nucleate boiling (DNB).

$\tau_{1}, \tau_{2}$ : time constants, to compensate the pipe and instrument time delay

$\tau_{3}, \tau_{4}$ : Lead/lag time constants, to compensate in the cold leg for RTD and thermowell thermal time constant less fluid transport time from the cold leg RTD to the core, or the hot leg RTD and thermowell time constant plus fluid transport time from the core to the hot leg RTD

$f_{1}(\Delta I)$ : The axial flux penalty function, $\Delta I$ is the measured neutron axial flux difference between the upper (top) and lower (bottom) power range neutron flux detectors.

As for, The setpoint ${ }^{[4]}$ calculation includes the correction of the density of water and heat capacity with temperature and the dynamic compensation for changes in the density of the water flowing through the reactor vessel downcomer.

\subsection{OP DeltaT Reactor Trip Function}

There are cold leg temperature measurements and hot leg temperature measurements in each reactor coolant system loop, to form four DeltaT (the difference of hot temperature and cold temperature) and average temperature $\left(T_{\text {avg }}\right)$ signals.

An overpower DeltaT RT shall be initiated if:

$$
\text { Margin } O P \Delta T=\Delta T_{\text {Setpoint }}-\Delta T\left(1+\tau_{6} s\right) /\left(1+\tau_{7} s\right)<0 \text { in two of the four } \Delta T
$$

The setpoint for DeltaT is variable:

$$
\Delta T_{\text {Setpoint }}=\Delta T_{0}\left[K_{4}-K_{5}\left(\tau_{3} s\right) /\left(1+\tau_{3} s\right) T_{\text {avg }}-K 6\left(T_{\text {avg }}-T_{\text {avg }}^{\prime}\right)-f_{2}(\Delta I)\right]
$$

$\Delta T$ : Temperature measurement by RTD and computed $\Delta T$, core thermal power, $\Delta T_{0}$ : Computed $\Delta T$ at rated thermal power, $T_{a v g}$ : Average temperature , $T_{a v g}^{\prime}$ : Average temperature at rated thermal power, $K_{4}$ : Offset, $K_{5}$ : Constants, It change to 0 when $T_{\text {avg }}$ descend, $K_{6}$ : Constants, It change to 0 when $T_{\text {avg }}$ less than $T_{\text {avg }}^{\prime}, \tau_{3}$ : time constants.

$\tau_{6}, \tau_{7}$ : Lead/lag time constants, to compensate in the cold leg for RTD and thermowell thermal time constant less fluid transport time from the cold leg RTD to the core, or the hot leg RTD and thermowell time constant plus fluid transport time from the core to the hot leg RTD

$f_{2}(\Delta I)$ : The penalty for adverse axial power distribution, linearly interpolated from a set of eight user defined input data points. DeltaI is the difference between the upper and lower calibrated ion chamber current readings.

\section{OVERTEMPERATURE AND OVERPOWER DELTAT SHUTDOWN FUNCTION UNDER THE CONDITION OF DIGITAL INSTRUMENT AND CONTROL}




\section{TECHNOLOGY}

\subsection{Hot leg temperature signal $\left({ }^{T_{h o t}}\right)$ processing}

According to the third generation nuclear power plant digital ${ }^{[5][6]}$ I\&C technology design, In each division, three temperature measurements from the associated hot leg, to form one TH signal. Each division monitors a separate hot leg. These detectors are fast-response RTDs installed in special thin-wall-design thermowells that improve their response characteristics for certain accident events. The detectors are located in the same plane perpendicular to the pipe centerline spaced $120^{\circ}$ apart. Three detectors function to provide a single input. This reduces the effects that hot leg streaming could cause on measured temperature uncertainty. Take the following measures to improve the accuracy of the signal:

\subsubsection{Filter The Measured Hot Leg Temperature}

For each of the measured temperature signal to be filtered first to minimize electrical noise and temperature fluctuations. The limit values of time response are specified for each RTD and its thermowell (for example, time response is no more than $4 \mathrm{~s}$ ) ${ }^{[7]}$. This design value is assumed to be the response time of the sensor in the safety analysis, as part of the response time of the whole channel. If the response time of RTD and thermowell is faster than the requirements, should be added another filter to reduce processing system and electrical noise. The lag time constant plus the actual RTD-thermovell thermal time constant must not exceed the allowable RTD-thermowell time constant specified as the design value.

\subsubsection{Steaming Correction}

Each of the measured hot leg temperature signals need to be corrected in order to make the corrected temperature signal equal to the optimal estimate of the average hot leg temperature. The correction value is proportional to the power, that is, the corrected value of zero power is zero, It is gradually increased with the power.

\subsubsection{Saturation Treatment}

The saturation temperature of the hot leg is measured as the limit value, which is not the safety limit of the core. In order to reduce the influence of the steaming, the temperature signal of each measured is compared with the saturation temperature of the coolant (the saturation temperature is determined by the pressurizer pressure). However, if the local temperature approaches saturation, then the RTD ceases to provide meaningful information regarding core power, and the value of the signal must be set to a unique high value. If only one of the three temperature channels is at high value, and the other signals are normal, then that signal will fail the redundancy test and be excluded from the group average. If two signals are set equal to the high value, then the group average will be a very high value that will trip the bistable in that division due to the very high value of the resultant $q_{\Delta T_{i}}$.

\subsubsection{Redundant Signal Algorithm (RSA)}

The $T_{\text {hot }}$ sensors are inherently redundant in the sense that two of the three sensors can adequately represent the $T_{\text {hot }}$ value. A comparison check of the three sensor signals will identify whether an individual signal has a substantial error (BAD sensor inputs are identified). In the event one of the three signals do not compare sufficiently closely to the other two, a good signal can be automatically identified by averaging the other two - provided they are sufficiently close to each other. The inputs to the algorithm are the individual $T_{\text {hot }}$ signals. Their states are defined in the algorithm output as a function of different combinations of the input $T_{\text {cold }}$ signals.

\subsubsection{Weighted Average}

Three temperature $T_{\text {hot }}$ signals have the difference electrical noise and steaming infect. This is a required algorithm based on engineering judgment. The group value $T_{\text {hot }}$ signal will be obtained by weighted average algorithm. If there are three signals without BAD sensor input, the comparison weighted average shall be computed as:

$$
T_{H}=\left[\sum\left(W_{i} T_{H i}\right)\right] /\left[\sum\left(W_{i}\right)\right]
$$


$T_{H i}$ : the $i^{\text {th }}$ RTD temperature signals, $i=1,2,3$

$W_{i}$ : An administratively controlled coefficient for the weighting factor for each individual hot leg RTD

When the temperature signal of a RTD is not involved in the weight calculation, the weight factor $W_{i}$ is not change, but $\sum\left(W_{i}\right)$ will be changed.

\subsubsection{Dynamic compensation}

In order to provide a more accurate coolant temperature, the temperature signal of hot leg and cold leg will be compensated by lead/lag. The leads and lags used for this dynamic compensation must equal the values assumed in the safety analysis. The lead/lag units are to advance or retard the temperature signals such that they correspond to reactor core conditions rather than the RTD temperature in the cold leg or hot leg piping. This dynamic compensation corrects for both the RTD and thermowell thermal time constant plus the fluid transport time from the RTD location to the core (or the core to the RTD location).

\subsection{Cold Leg Temperature Signal $\left({ }^{T_{\text {cold }}}\right)$ Processing}

In Overtemperature DeltaT and Overpower DeltaT protection design, the calculation of the $T_{\text {cold }}$ is the same with $T_{\text {hot }}$ calculation, but only some difference as flowing:

Due to there is no significant temperature steaming in the cold leg, there are two temperature signals in the cooling pipe. In the same way, the temperature signal of the cooling section is modified to get the best estimate of the average cold leg. Don't need saturation algorithm.

Two cold temperature signals deviate from each other more than a preset value, the RSA will compare the $T_{\text {cold }}$ with the desired $T_{\text {cold }}$ (from the power and the pressure of the steam pipeline). If the value is within the limit, then the calculation is used. If the temperature signals of the two cold leg are not allowed within the allowable limits, the cold leg signal in the division is marked as BAD quality. If the two signals do not compare sufficiently closely or if one has BAD sensor input, then a good signal can be automatically identified by comparison with other process variables.

This dynamic compensation corrects for both the RTD and thermowell thermal time constant minus the fluid transport time from the RTD location to the core (or the core to the RTD location).

\subsection{Overpower DeltaT Calculation}

An Overpower DeltaT (OPDeltaT) RT shall occur if the core thermal power in two of four (2/4) divisions, exceeds the overpower setpoint (including a penalty for adverse axial power shape). The core thermal power is computed from hot leg and cold leg temperatures and pressurizer pressure and based on the state properties of water in the hot and cold legs, and the essentially constant volumetric flow in the cold leg. This signal is the DeltaT power signal $q_{\Delta T}$, used in both the OPDeltaT and OTDeltaT RTs, and also used as a primary loop power signal in various other PMS algorithms.

The equations for the DeltaT power signal:

$$
\begin{gathered}
q \Delta T=f\left(T_{H}, T_{C}, T_{P Z F}\right) \quad(\text { the } \Delta T \text { power signal }) \\
q \Delta T=\rho\left(T_{C}, T_{P Z F}\right)\left[h\left(T_{H}, T_{P Z F}\right)-h\left(T_{C}, T_{P Z F}\right)-C\right] / \Delta T^{\circ}
\end{gathered}
$$

Where, $T_{H}$ and $T_{C}$ are dynamically compensated values of $T_{\text {нот }}$ and $T_{\text {СоLD }}$

$$
\begin{array}{cc}
T_{C}=\left(1+\tau_{1} s\right) /\left[\left(1+\tau_{2} s\right)\left(1+\tau_{3} s\right)\right] T_{\text {cold }} \quad\left(T_{\text {cold }} \text { lag filter and lead } / \text { lag }\right) \\
T_{H}=\left(1+\tau_{4} s\right) /\left[\left(1+\tau_{5} s\right)\left(1+\tau_{6} s\right)\right] T_{\text {hot }} \quad\left(T_{\text {hot }} \text { lag filter and lead / lag }\right)
\end{array}
$$

$T_{C}$ and $T_{H}$ are the dynamically compensated cold and hot core temperatures. $T_{\text {cold }}$ and $T_{\text {hot }}$ are cold leg and hot leg division group average values (weighted average temperatures from RTD signals).

$\tau_{1}, \tau_{2}$, and $\tau_{3}$ compensate for the RTD thermowell and initial filter response time, minus cold leg to core mid-plane fluid-transport time). $\tau_{4}, \tau_{5}$, and $\tau_{6}$ compensate for the RTD thermowell and initial filter response time, plus core mid-plane to hot leg fluid-transport time.

Values $\tau_{1}$ to $\tau_{6}$ must be set equal to the values assumed in the accident analyses. Larger (or 
smaller) values will be conservative for some events and non-conservative for other events. Typical values of $\tau_{1}, \tau_{2}$, and $\tau_{3}$ are 4, 1.5, and 1.5 seconds ( 1 second net lead). Typical values of $\tau_{4}, \tau_{5}$, and $\tau_{6}$ are 10,2 , and 2 seconds (6 second net lead).

$P_{P Z R}$ is the pressurizer pressure, $\rho\left(T_{C}, T_{P Z F}\right)$ is the cold leg density, $h\left(T_{H}, T_{P Z F}\right)$ and $h\left(T_{C}, T_{P Z F}\right)$ are hot leg and cold leg enthalpies, $C$ is bias to zero $q_{\Delta T}$ at zero power (correct small $T_{\text {hot }}$ and $T_{\text {cold }}$ errors)

$\Delta T^{0}$ is conversion coefficient to make $q_{\Delta T}$ equal to 100 percent at RTP

\subsection{Overpower DeltaT Setpoint Calculation and Trip}

\subsubsection{Overpower DeltaT Setpoint Calculation}

Overpower DeltaT setpoint calculation is continuous by online, and based on an input constant as modified by the axial offset penalty $f_{2}(\Delta I)$ for adverse axial power distribution:

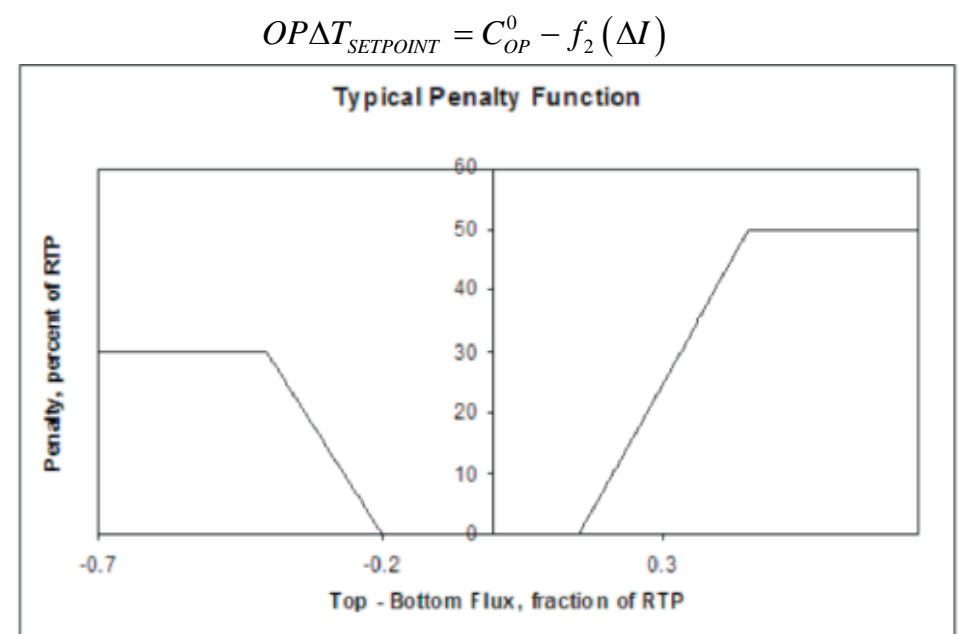

Figure 3.4.1-1 Illustration of Axial Flux Penalty Function

Where, $C_{O P}^{0}$ : The overpower DeltaT setpoint for normal axial power distribution (manually selected input)

$f_{2}(\Delta I)$ : The penalty for adverse axial power distribution, linearly interpolated from a set of eight user defined input data points

$\Delta I$ : The difference between the upper and lower calibrated ion chamber current readings.

The function defined by a typical table is shown graphically in Figure 3.4.1-1. $\Delta I$ is the measured neutron axial flux difference between the upper(top) and lower (bottom) power range neutron flux detectors. When the $\Delta I$ is more than the operational band, will cause the reactor trip setpoint degrade faster than before. There exist a risk for unanticipated reactor trip. So it need add the algorithm penalty function.

\subsubsection{Overpower DeltaT margin to trip}

The using of digital technology, a single overpower DeltaT shutdown margin signal does not generate the error or increase the delay. This allows lead/lag compensation to shutdown margin signal, thereby compensating reactor shutdown delay, such as instrument, reactor trip breakers break, control rod release, and when the control rods drop to the reactor core, rapid introduction of negative reaction.

An Overpower DeltaT (OPDeltaT) RT shall occur if the core thermal power is negative in two of four (2/4), then $q_{\Delta T}$ exceeds the overpower setpoint (including a penalty for adverse axial power shape).

$$
\operatorname{Margin}_{O P \Delta T}=\left[O P \Delta T_{\text {SETPOINT }}-q \Delta T\right]\left(1+\tau_{7} s\right) /\left[\left(1+\tau_{8} s\right)\left(1+\tau_{9} s\right)\right]
$$

$q_{\Delta T}$ : Core thermal power as determined by $T_{H}$ and $T_{C}$

$\tau_{7}, \tau_{8}, \tau_{9}$ : Lead and lag setpoint provided to compensate, for protection system and RCCA delays in reducing core power.

\subsection{Overtemperature DeltaT Setpoint Calculation and Trip}

3.5.1 Overtemperature DeltaT Setpoint Calculation 
The computation shall be done by interpolation from input tables for the DNB thermal design limits as a function of cold leg (core inlet) temperature and pressure. These calculations shall be corrected if an adverse core axial power distribution exists by using the following function:

$$
\begin{gathered}
\text { OT } \Delta T_{\text {SETPOINT }}=O T \Delta T_{\text {SETPOINT }}^{0}-f_{1}(\Delta I) \\
\text { OT } \Delta T_{\text {SETPOINT }}^{0}=f\left(P_{P}, T_{C}\right)
\end{gathered}
$$

$O T \Delta T_{\text {SETPOINT }}^{0}$ : The core DNB thermal design limit, in percent of RTP, with design axial power distribution

$T_{C}$ : It is dynamically (lead/lag) compensated $T_{\text {cold }}$, representing the core inlet temperature (the same signal as in the $q_{\Delta T}$ power signal)

$P_{P}$ : It is the lower of $P_{P Z R}$ and $P_{P Z R}$ with lead/lag compensation (the same lead/lag signal as used for the pressurizer Low-2 pressure RT). This is conservative for a pressure decrease, but not nonconservative for a pressure increase. The empirical DNB correlation, on which the core limits are based, has a range of RCS pressure over which it is applicable. This same pressure range, therefore, also applies to the OTDeltaT setpoints that are based on the core limits. The pressurizer Low- 2 pressure RT limits the pressure range for which the OTDeltaT RT must provide protection consistent with the limits of the DNB correlation. No limit is needed for high pressure, as that limit is satisfied within the OTDeltaT function itself.

$f_{1}(\Delta I)$ : It is the power penalty for adverse axial shape penalty allowance for uncertainty and errors included in $O T \Delta T_{\text {SETPOINT }}^{0}$ and does not require a separate margin between the $f_{1}(\Delta I)$ safety limit and the $f_{1}(\Delta I)$ setpoint.

$\Delta I$ : It is the measured neutron axial flux difference between the upper (top) and lower (bottom) power range neutron flux detectors.

The function is specified as tables for six pressures and seven sets of core limit power, q. versus $T_{C}$ for each pressure. For any pressure, interpolation is done by first determining a one-dimensional table of $q(T)$ for that pressure by linear interpolation of all seven $q\left(T_{C}\right)$ pairs for the pressures above and below Pressurizer pressure. If the Pressurizer pressure is greater than the maximum table pressure (or less than the minimum table pressure), the maximum table pressure (or the minimum table pressure) is to be used. That is, no pressure extrapolation outside the range of the tables. This is conservative for high pressure, and immaterial for low pressures since the Low-2 pressure RT must be set above the minimum table pressure. Similarly, for each pressure, if the $T_{C}$ is greater than the maximum table temperature (or less than the minimum table temperature), the maximum table temperature (or the minimum table temperature) is to be used. Second, the allowable power ( OT $\Delta T_{\text {SETPOINT }}^{0}$ ) is determined by linear interpolation of the resulting $q(T)$ table for $T_{C}$ for that division. There is no unique linear interpolation method for non-linear, non-parallel lines with non-uniform breakpoints. This order of calculation is specified as the most consistent with the physical basis for the DNB core limits.

As an example, consider the value of $о T \Delta T_{\text {SETPoINT }}^{0}$ that should be determined for $T_{C}$ of $574.5^{\circ} \mathrm{F}$

(301.39 ${ }^{\circ} \mathrm{C}$ ) and pressurizer pressure of 2250 psia (15.513 MPa), given the following core limits at 2200 psia (15.168 MPa) and 2400 psia (16.547 MPa) as shown in Table 3.5.1-1:

TABLE 3.5.1-1 Example Partial Table for DNB Thermal Design Limit

\begin{tabular}{cccc}
\hline \multicolumn{2}{c}{ 2200psia(15.168MPa) } & \multicolumn{2}{c}{ 2400psia(16.547MPa) } \\
\hline $\mathrm{TC} /$ & Power/ & $\mathrm{TC} /$ & Power/ \\
${ }^{\circ} \mathrm{F}\left({ }^{\circ} \mathrm{C}\right)$ & $\begin{array}{c}{ }^{\circ} \mathrm{F}\left({ }^{\circ} \mathrm{C}\right) \\
\text { Percent of }\end{array}$ & & Percent of \\
& RTP & $0(-17.78)$ & 140.0 \\
$0(-17.78)$ & 130.0 & $540(279.49)$ & 140.0 \\
$535(279.49)$ & 130.0 & $570(301.67)$ & 130.0 \\
$575(301.67)$ & 120.0 & $590(310.0)$ & 110.0 \\
$590(310.0)$ & 100.0 & $590.1(310.06)$ & 0.000 \\
$590.1(310.06)$ & 0.000 & & \\
\hline
\end{tabular}




\begin{tabular}{llll}
$700(371.11)$ & 0.000 & $700(371.11)$ & 0.000 \\
\hline
\end{tabular}

Interpolation as specified above will yield 121.577 for $O T \Delta T_{\text {SETPOINT }}^{0}$ at 2250 psia (15.513 MPa) and $T_{C}$ of $574.5^{\circ} \mathrm{F}\left(301.39^{\circ} \mathrm{C}\right)$. The calculation is shown graphically in Figure 3.5.1-1.

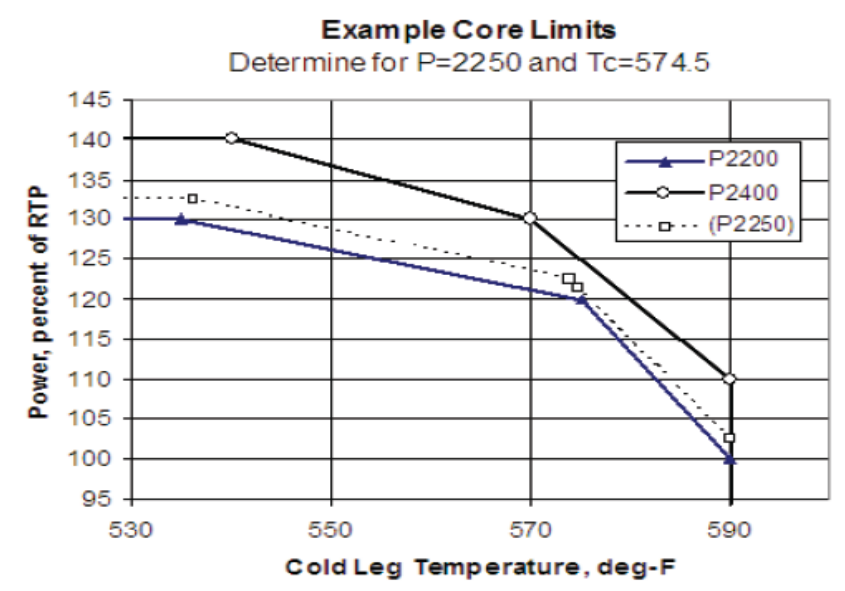

Figure 3.5.1-1 Example Interpolation of DNB Thermal Design Limits

3.5.2 Overtemperature DeltaT margin to trip

The using of digital technology, a single overtemperature DeltaT shutdown margin signal does not generate the error or increase the delay. This allows lead/lag compensation to shutdown margin signal, thereby compensating reactor shutdown delay, such as instrument, reactor trip breakers break, control rod release, and when the control rods drop to the reactor core, rapid introduction of negative reaction.

An Overtemperature DeltaT (OTDeltaT) RT shall occur if the margin is negative in two of four (2/4), then $q_{\Delta T}$ exceeds the overtemperature setpoint.

$$
\text { Margin }_{\text {OP } \Delta T}=\left[O T \Delta T_{\text {SETPOINT }}-q_{\Delta T}\right]\left(1+\tau_{10} s\right) /\left[\left(1+\tau_{11} s\right)\left(1+\tau_{12} s\right)\right]
$$

$q_{\Delta T}$ : DeltaT power signal, Core thermal power

$\tau_{10}, \tau_{11}$, and $\tau_{12}$ are lead and lag setpoints provided to compensate, if necessary, for protection system and control rod insertion delays in reducing core power. The net lead is $\tau_{10}-\left(\tau_{11}+\tau_{12}\right)$.

\section{IMPROVEMENT OF THE DIGITAL PROTECTION ALGORITHM WITH THE TRADITIONAL ANALOG ALGORITHM}

Upon description, compared with the analog technology algorithm, digital protection algorithm has made many improvements ${ }^{[8]}$, mainly in the following:

The conversion of the core thermal limit to protection setpoint is more simple. A new protection system setpoint interpolation are from the DNB thermal limit, which is according to the coolant system pressure and cold leg temperature, thermal design limit power based on the given protection setpoint. After using the digital system, the performance of the thermal power monitoring and protection system is improved. The thermal calculation formula is adopted to obtain the accurate thermal power level of the reactor. Don't use the $T_{\text {avg }}$ and $\Delta T$ calculation method, compare with measuring the thermal power and the theoretical thermal power setpoint and obtain the shutdown margin, which makes the algorithm is easier to understand, more accurate and easier to monitor and improve the performance of the system. The directly use of cold leg and hot leg temperature, without the use of the average temperature and the $\Delta T$ temperature, makes the instrument delay and fluid transfer time of the dynamic compensation is simplified. The overtemperature $\Delta T$ setpoint is a function of cold leg (core inlet) temperature and pressure, so the reactor shutdown conditions depend on the inlet temperature. DNBR calculation based on the core inlet temperature, the overtemperature $\Delta T$ setpoint only need to consider a certain margin on the basis of DNB limits and the appropriate uncertainty. 
In order to ensure the normal operation of the transient does not actuate protection function, the protection of digital I\&C mainly take the following two measures. First, It has enough margin. The overtemperature $\Delta T$ is $118.72 \%$ at full power greater than power range high neutron flux reactor trip setpoint (109\%). Second, it is more margins for $f_{1}(\Delta I)$ dead band. At the normal operation condition, the $\Delta I$ value works to the 0 area. So it can get more operational margin ${ }^{[9]}$.

\section{CONCLUSION}

Overtemperature $\Delta T$ and overpower $\Delta T$ shutdown protection function is important to prevent the core heat removal difficult damage the reactor. Before the reactor trip ${ }^{[10]}$ setpoint, it will produce runback signal, which reduce the primary loop reactor power and second loop turbine load. After using the digital instrument and control system, the protection algorithm and the signal processing method are improved, and the performance of these two kinds of protection functions is improved.

\section{REFERENCES}

[1] Mistubishi Heavy Industries Overtemperature DeltaT and Overpower DeltaT Reactor Trip Functions and Setpoint Determination Process, MUP-11014 (R0) [R]. Tokyo: Mistubishi Heavy Industries, 2012.

[2] Mistubishi Heavy Industries. US-APWR Instrument Setpoint Methodology, MUAP-07009-NP (Non-Proprietary) [R]. Tokyo: Mistubishi Heavy Industries, 2012.

[3] NRC Standard Technical Specification Westinghouse Plants, NUREG-1431, Rev.2 [R].Washington D.C.: NRC, 2001.

[4] LI Jingwei, overtemperature and overpower protection setpoint design for Qin shan Phase II NPP Project, Nuclear power engineering, 2003(SI): 20-24

[5] Xu Zhi, Analysis on the application of OP $\Delta T$ /OT $\Delta T$ protection for AP1000 [J]. Nuclear Safety,2014,13(3):39-44

[6] BTP 7-21, Guidance on digital computer real-time performance [S]. Rock Ville: NRC, 2007

[7] IEEE standard for criteria for the periodic surveillance testing of nuclear power generating station safety systems[R]. IEEE Std 338,2012

[8] LIN Chengge, Yu Zusheng. Passive safety advanced pressurized water reactor technology[M].Beijing, Atomic Energy Press, 2008:150-176

[9] PU Jilong, Guangdong Daya Bay nuclear power plant operation tutorial [M]. Beijing: Atomic Energy Press, 1999:214-241

[10] WANG Jinging, Analysis and test of respond time of nuclear power plant digital control system to reactor trip [J]. Nuclear Power Engineering, 2012,33(2):5-10 